\title{
PHYLLODES TUMORS OF THE BREAST: A RETROSPECTIVE EVALUATION OF CASES FROM THE HOSPITAL DO SERVIDOR PÚBLICO ESTADUAL DE SÃO PAULO \\ Tumor filoides de mama: avaliação retrospectiva de casos do Hospital do Servidor Público Estadual de São Paulo
}

Ana Beatriz Tavares de Moura Brasil Matos*, Joaquim Teodoro de Araujo Neto², Marcelo Antonini', Odair Ferraro19, Bruno de Carvalho Mancinelli³, Ana Maria Gomes Pereira1,3, Reginaldo Guedes Coelho Lopes ${ }^{1,3}$

\section{ABSTRACT}

Objective: To evaluate the clinical and pathological characteristics of phyllodes tumors, and to identify possible associated risk factors for relapses among patients from the Breast Surgery Department of the Hospital do Servidor Público Estadual of São Paulo (HSPE-SP). Methods: Retrospective, descriptive study of data from 52 patients, between 1976 and 2013. The following data were collected: age, tumor size, histological type, surgical margins, type of surgery performed, relapses and amount of time before relapse. Results: The mean age of the patients was 45.7 years old, the mean size of the tumor was $7.8 \mathrm{~cm}$. A mastectomy was performed on 12 patients, and the others underwent a wide excision. Benign phyllodes tumors were found in 30 patients, and the others were found as follows: 11 with borderline tumors and 11 with malign phyllodes tumors. There was no statistical relevance with regard to the relapses and the characteristics evaluated. Conclusion: The sample studied has similar clinical and pathological characteristics as described in the scientific literature, with the mean age at diagnosis being 45 years old, the mean tumor size, $7.8 \mathrm{~cm}$. The majority found were benign phyllodes tumors and 33\% were from relapses. There was no statistical significance between the evaluated variables and the risk for relapse.

KEYWORDS: Breast disease; Surgery; breast tumors; Phyllodes tumors; breast.

\section{RESUMO}

Objetivo: Avaliar as características clínicas e patológicas do tumor filoides e identificar fatores relacionados com risco de recidivas em pacientes acompanhadas no ambulatório de Mastologia do Hospital do Servidor Público Estadual de São Paulo (HSPE-SP). Método: Estudo retrospectivo descritivo de dados de 52 pacientes, entre 1976 e 2013, dentre os quais: idade, tamanho do tumor, tipo histológico, margens cirúrgicas, tipo de cirurgia, recidivas e tempo para recidiva. Resultados: A idade média das pacientes foi 45,7 anos. O tamanho médio do tumor foi de $7,8 \mathrm{~cm}$. O tratamento em 12 pacientes foi a mastectomia, e as demais 40 a excisão ampla. O tipo histológico encontrado em 30 pacientes foi tumores benignos, 11 malignos e 11 de variedade borderline. Após o seguimento médio de 53,93 meses, observaram-se 17 recidivas. Não houve relevância estatística entre a recorrência local e as variáveis avaliadas. Conclusões: A amostra avaliada tem características clínicas e patológicas condizentes com a literatura, com média de idade de 45 anos, tamanho do tumor de $7,8 \mathrm{~cm}$, sendo encontrados na maioria tumor filoides benigno e $33 \%$ de recidivas. Não houve significância estatística entre características avaliadas e o risco de recidiva.

PALAVRAS-CHAVE: Doenças da mama; cirurgia; tumores de mama; tumor filoide; mama.

Study carried out at the Hospital do Servidor Público Estadual Francisco Morato de Oliveira - São Paulo (SP), Brazil.

${ }^{1}$ Hospital do Servidor Público Estadual Francisco Morato de Oliveira - São Paulo (SP), Brazil.

${ }^{2}$ Paulista School of Medicine, Universidade Federal de São Paulo - São Paulo (SP), Brazil.

${ }^{3}$ Instituto de Assistência Médica ao Servidor Público Estadual - São Paulo (SP), Brazil.

*Corresponding author: matos.anabeatriz@gmail.com

Conflict of interests: nothing to declare.

Received on: 09/25/2017. Accepted on: 09/25/2017. 


\section{INTRODUCTION}

Phyllodes tumor of the breast is a rare type of neoplasm, and accounts for less than $1 \%$ of all breast tumors ${ }^{1-3}$. It was described in 1838 by Johannes Mueller, under the name of Cystosarcoma Phyllodes, for having cystic content (cysto), flesh-like aspects (sarcoma) and foliaceous extensions (phyllodes) ${ }^{4,5}$.

The etiology of phyllodes tumors remains unknown. They mainly appear women and rarely occur in the male sex. Only nine cases have been described in the literature of men with gynecomastia. Its incidence is apparently higher in white women, in the age group of 35-55 years old 6 .

In 1982, the World Health Organization (WHO) ${ }^{7}$ grouped more than 60 types of tumors in the classification of phyllodes tumors, because it was the most appropriate classification for grouping all of their characteristics. After the study done by Trevor, Norris and Azzopardi, the WHO adopted the pathological subclassifications of benign, borderline and malignant, which are used today (Chart 1). However, the classifications do not predict the clinical and biological behavior of this neoplasm ${ }^{1,8-10}$.

Histologically, phyllodes tumors are diverse with regard to the way they present themselves. Sometimes they resemble fibroadenoma and, at other times, they resemble a low-grade sarcoma, since these tumors are formed by epithelial and stromal elements of the breast. Characteristically, their intracanalicular growth pattern resembles a tree leaf ${ }^{4,5}$. The classification into benign, malignant or borderline is done by analyzing the tumors' stromal components: stromal cell atypia, mitosis index, stromal cellularity and aspects of the margins ${ }^{1-3,5}$.

Benign phyllodes tumors are characterized by the absence of or the mild presence of stromal cellular atypia, discrete or circumscribed stromal hypercellularity, circumscribed margins, and mitotic activity of less than 5 mitoses per 10 high-power fields (10 HPF). Borderline tumors have mild or moderate stromal atypia, moderate hypercellularity, circumscribed or infiltrative margins, and mitotic activity between 5-10 mitoses per 10 HPF. Malignant phyllodes tumors are characterized by pronounced stromal atypia, enhanced, usually marked and diffuse hypercellularity, infiltrative margins, and a mitosis index greater than 10 mitoses per $10 \mathrm{HPF}^{5,11}$.

A phyllodes tumor macroscopically is a circumscribed, rounded or oval-shaped nodule, which may be multinodular and devoid of a true capsule. The literature reports tumor sizes from $1 \mathrm{~cm}$ to larger than $40 \mathrm{~cm}$. Upon macroscopic examination, phyllodes tumors are quite similar to fibroadenoma $a^{4,5}$.

Clinically, it is a single, unilateral, solid, rapidly growing, large-sized tumor that can cause bulging, distortion or ulceration of the $\operatorname{skin}^{1,2,12}$. There are no determinant risk factors for the onset of phyllodes tumors, but patients with a p53 mutation and Li-Fraumeni syndrome are at a high risk for developing these lesions 5 .
The diagnosis of phyllodes tumors should be made using both medical history and physical examination. Complementary imaging studies may show lesions that are often confused with fibroadenoma. Even the anatomopathological analysis of the material obtained by biopsy, either by fine needle aspiration (FNA) or by fragment biopsy, raises doubts about the etiology of the tumor ${ }^{3,5}$.

If, clinically, there is suspicion that the tumor is present, surgical treatment for the complete removal of the lesion with adequate margins is the standard procedure, and a broad excision with margins, or even a simple mastectomy may be indicated to avoid recurrences ${ }^{1,3,13,14}$.

The prognostic factors associated with relapses are still not well established. Ward et al. describes stromal hypercellularity as a factor that would influence the prognosis ${ }^{5}$. Later, in 1991, Cohn-Cedermark et al. included tumor necrosis and the presence of different fibromixoid tissue factors among the prognostic factors ${ }^{16}$.

A study by Mokbel et al. ${ }^{17}$, demonstrated that there is an association between the local recurrence of phyllodes tumors and the histological type, with a higher recurrence rate among patients with malignant phyllodes tumors.

Other case series studies, such as the one carried out by Roos et al. ${ }^{18}$, observed that local recurrence was more significant when the surgical margins were affected by the tumor.

This study aims to evaluate the clinical and pathological characteristics of the phyllodes tumor in patients treated at the mastology outpatient clinic of the Hospital do Servidor Público Estadual de São Paulo. It compares them with those in the literature, and also evaluates if there is any risk factor associated with the recurrence of phyllodes tumors after surgical treatment.

\section{METHODOLOGY}

A retrospective analysis of medical records was carried out with patients from the Hospital do Servidor Público Estadual de São Paulo, from 1993 to 2013, who had a clinical and histopathological diagnosis of phyllodes tumors and who underwent treatment at the mastology outpatient clinic. Only medical records of patients that were confirmed to have a histopathological tumor type were included in the study, totaling 29 cases. Cases that were not confirmed to be histopathological, like benign tumors such as fibroadenoma, and malignant tumors such as breast cancer and sarcomas, were not included (Table 1).

This study included data from the series of 23 cases of the retrospective study on phyllodes tumors carried out in the same hospital from 1976 to 1992, by Araújo Neto et al., and published in Mastology - the Official Journal of the Brazilian Society of Mastology - in $1999^{4}$. There was a total of 52 cases.

The clinical and histopathological aspects of each patient that were contained in the medical records were reviewed. Data such as age at diagnosis, affected breast, type of surgery performed, 
tumor size, follow-up time, and relapses, were collected. With regard to the histopathological diagnosis, the margins were evaluated and were considered to be free when they were greater than or equal to $1 \mathrm{~mm}$. The tumors were classified according to the WHO's categories ${ }^{7}$ into benign, borderline and malignant. The data were distributed in a standardized table using Microsoft Office Excel 2013 for interpretation.

The study by Araújo Neto et al. ${ }^{4}$ did not analyze surgical margins or the histological type of the tumor and relapse. Thus, a statistical analysis was performed with only 30 patients, in which it was possible to describe the data about the surgical margins and the histological type of tumor, in which there were recurrences. Other data were evaluated together.

A descriptive and retrospective data analysis was performed. For the statistical analysis of the results, the SPSS 22.0 software was used, considering $p$ (level of descriptive significance) less than 0.05 as significant.

\section{RESULTS}

The mean age of the patients at the time of diagnosis was 45.7 years old (and ranged from 17-82 years old). The mean tumor size was $7.8 \mathrm{~cm}$ (and ranged from 3 to $17 \mathrm{~cm}$ ). Of the total number of patients, 12 underwent a mastectomy. The remaining 40 underwent an extensive excision procedure. Of the 52 tumors examined, 30 were benign, 11 were malignant, and 11 were borderline. After the mean follow-up of 53.93 months, 17 recurrences were observed (Table 2).

Among the 30 patients whose data on surgical margins and histological type of relapse could be determined, there were nine recurrences, all of which were initially submitted to extensive excision. Three had margins that were compromised by the tumor after the surgery. Among the nine relapses, five of the initial tumor types were benign, three were malignant and one was borderline, as shown in Tables 3 and 4 .

The association between local recurrence and histological type was not statistically relevant (Table 5). There was also no relevant statistical association between tumor size and local recurrence.

No significant statistical difference was observed with regard to the age of diagnosis among patients with local recurrence and patients without it.

\section{DISCUSSION}

Phyllodes tumor of the breast is a rare disease, occurring mostly in women aged between $35-55$ years old 6 . The study by Lenhard et al. ${ }^{6}$ with a sample of 33 cases, had an average age of 47 years old. The study by Hassouna et al. ${ }^{19}$, with a sample of 106 patients, had a mean age of 39.6 years old, and Karim et al. ${ }^{20}$ reported a mean age of 43 years old. The present study demonstrates a similar finding regarding the diagnostic age range, with a mean of 45.7 years old. This reinforces data described in the literature about the age group with the highest rate of onset.

In the studied sample, the mean tumor size found after the histopathological analysis was performed was $7.8 \mathrm{~cm}$, with a wide range of sizes from 3 to $17 \mathrm{~cm}$. The series of case studies in the literature show varying results, such as 0.5 to $25 \mathrm{~cm}$ in the study by Hassouna et al. ${ }^{19}$, and 0.4 to $29 \mathrm{~cm}$ in the study by

Table 2. Characteristics of patients and treatment modalities.

\begin{tabular}{|c|c|}
\hline \multicolumn{2}{|l|}{ Age (years) } \\
\hline Mean & 45.7 \\
\hline Interval & $17-82$ \\
\hline \multicolumn{2}{|l|}{ Size $(\mathrm{cm})$} \\
\hline Mean & 7.8 \\
\hline Interval & $3-17$ \\
\hline \multicolumn{2}{|l|}{ Type of surgery } \\
\hline Broad excision & $40(77.0 \%)$ \\
\hline Mastectomy & $12(23.0 \%)$ \\
\hline \multicolumn{2}{|c|}{ Histological type of tumor } \\
\hline Benign & $30(57.8 \%)$ \\
\hline Borderline & $11(21.1 \%)$ \\
\hline Malignant & $11(21.1 \%)$ \\
\hline \multicolumn{2}{|l|}{ Surgical margins } \\
\hline Free & $22(73.3 \%)$ \\
\hline Affected & $8(26.7 \%)$ \\
\hline Recurrences & $17(33.0 \%)$ \\
\hline Total patients & 52 \\
\hline
\end{tabular}

Values in parentheses are the percentages. The margins that were considered free were those in which "cells do not touch the ink". In this study, only information about the margins of 30 patients was obtained.

Table 1. Histological classification of phyllodes tumors.

\begin{tabular}{l|c|c|c} 
Characteristic & Benign & Borderline & Malignant \\
Mitotic activity & $<5 / 10 \mathrm{HPF}$ & $5-9 / 10 \mathrm{HPF}$ & $>=10 / 10 \mathrm{HPF}$ \\
\hline Stromal atypia & Absent or mild & Mild or moderate & Enhanced \\
\hline Stromal cellularity & $\begin{array}{c}\text { Discrete, non-uniform or } \\
\text { diffuse hypercellularity }\end{array}$ & $\begin{array}{c}\text { Moderate, non-uniform or } \\
\text { diffuse hypercellularity }\end{array}$ & $\begin{array}{c}\text { Enhanced, usually marked and } \\
\text { diffuse hypercellularity }\end{array}$ \\
\hline Margins & Circumscribed & Circumscribed or infiltrative & Infiltrative \\
\hline
\end{tabular}

Source: World Health Organization?. 
Table 3. Characteristics of patients with a recurrence of phyllodes tumors.

\begin{tabular}{l|c}
\hline Age (years) & 45.7 \\
\hline Mean & $17-64$ \\
\hline Interval & 8.1 \\
\hline Size (cm) & $4-15$ \\
\hline Mean & \\
\hline Interval & $14(82.3 \%)$ \\
\hline Type of surgery & $3(17.7 \%)$ \\
\hline Broad excision & \\
\hline Mastectomy & $9(53.0 \%)$ \\
\hline Histological type of tumor & $5(29.4 \%)$ \\
\hline Benign & $3(17.6 \%)$ \\
\hline Marderline & 37.8 \\
\hline Disease-free interval (months) & $5-120$ \\
\hline Mean & 17 \\
\hline Interval & \\
\hline Total patients & \\
\hline
\end{tabular}

There was no result with $p<0.05$.

Table 4. Surgical margins in 9 recurrences of phyllodes tumors.

\begin{tabular}{l|c} 
Surgical margins & \\
Free & $6(66.6 \%)$ \\
\hline Affected & $3(33.3 \%)$ \\
\hline Total patients & 9 \\
\hline
\end{tabular}

$\mathrm{p}=0.244 ; \mathrm{Cl}=0.473$ to 19.039 .

Table 5. Histological type of the recurrence of 30 patients with phyllodes tumor recurrence.

\begin{tabular}{l|c}
\multicolumn{2}{l}{ Histological type of recurrence } \\
\begin{tabular}{l|c} 
Benign & $4(44.4 \%)$ \\
\hline Borderline & $3(33.3 \%)$ \\
\hline Malignant & $2(22.2 \%)$ \\
\hline Total patients & 9 \\
\hline
\end{tabular}
\end{tabular}

In this study, information about histological type of recurrence was obtained only in 9 patients.

Spitaleri et al. ${ }^{1}$. No study was able to statistically establish any significant relationship between tumor size and local recurrence. Despite the fact that there was no statistical significance, it is possible to observe in the literature that local control is hampered by larger tumors. Patients with tumors larger than $5 \mathrm{~cm}$ have a lower chance of survival according to a study by Belkacemi et al. ${ }^{21}$.
Phyllodes tumors are usually treated with wide excision surgery with adequate margin resection. Simple enucleation should be avoided. Obtaining an adequate margin of normal breast tissue - about 1 or $2 \mathrm{~cm}$ for some studies and negative margin for others - is especially important in the case of borderline or malignant tumors, since surgical margins are the best predictor of local recurrence ${ }^{6,16}$.

Mastectomy is no longer considered the treatment of choice for phyllodes tumors, even borderline or malignant ones, in cases in which wide excision with margins is feasible, since local recurrence is not associated with systemic metastases and can be treated with a new wide excision ${ }^{1,4,6,16,21}$.

In this study, malignant and borderline tumors accounted for an incidence rate of $21.1 \%$ each, indicating a total of $42.2 \%$. This incidence was similar to that found in the literature review, carried out by Spitaleri et al. (2013) ${ }^{1}$, who analyzed 5,530 patients and found malignant and borderline phyllodes tumors in about $48 \%$, almost half of the sample. Another series of case studies by Mokbel et al. (1999) ${ }^{17}$ with 30 patients, and Belkacemi et al. $(2008)^{21}$ with 443 patients, showed a slightly lower incidence, with 30 and $36 \%$, respectively, between borderline and malignant tumors.

Due to the rarity of this neoplasm and the difficulties in anatomopathological classification, many discordant results are found in the literature. Authors, in order to obtain a relevant number of patients for the statistical analysis, seek cases in extensive databases with samples from many years, which in turn damages the homogeneity of the studied group. An example of this is the diversity of the prevalence of histological types, since this anatomopathological analysis is observerdependent. Despite the established criteria for diagnosis, differences in each medical professional's analysis and individual perception always exist. In addition, since 1982, there have been several histological reclassifications of phyllodes tumors, which impairs the uniformity of the data.

In this study, the percentage of large excision procedures with adequate margins among the 30 patients that could be evaluated was $86.7 \%$. Of these, $26.7 \%$ had margins that were compromised by the disease, which was 8 patients. In the group of patients with compromised margins, half had recurrence. In spite of the impairment of the prevailing margin in the studies as a factor that leads to recurrence ${ }^{5,17,19,21,22}$, the present study did not succeed in statistically corroborating this relationship, probably due to the small number of patients in the sample.

\section{CONCLUSION}

The sample of patients analyzed at the Hospital do Servidor Público Estadual de São Paulo has similar clinical and pathological characteristics to those in the literature, with a mean age of 45 years, and a tumor size of $7.8 \mathrm{~cm}$. Mostly benign phyllodes tumors were found and $33 \%$ had relapses. 
It was not possible to infer if any of the characteristics evaluated influenced the recurrence of phyllodes tumors. This is justified by the low incidence of this tumor, resulting in a small sample. The literature review on the subject also cannot demonstrate studies that definitively associate one factor as the prognosis or the predictor of recurrence, which reinforces the difficulty in understanding and defining the biological behavior of this rare neoplasm. Further work and studies need to be conducted to determine prognostic and predictive factors for the recurrence of phyllodes tumors.

\section{REFERENCES}

1. Spitaleri G, Toesca A, Botteri E, Bottiglieri L, Rotmensz N, Boselli S, et al. Breast phyllodes tumor: A review of literature and a single center retrospective series analysis. Crit Rev Oncol Hematol. 2013;88:427-36.

2. Lima LNB, Pedrosa MC, Novita G, Luzzatto F, Frasson A. Tumores não epiteliais. In: Frasson A, Millen E, Novita G, Zerwes F, Brenelli F, Luzzatto F, et al. Doenças da Mama. São Paulo: Atheneu; 2013. p.359-64.

3. Foxcroft LM, Evans EB, Porter AJ. Difficulties in the preoperative diagnosis of phyllodes tumours of the breast: A study of 84 cases. The Breast. 2007;16:27-37.

4. Araújo Neto JT, Depes D, Alcântara M, Ferraro O, Baracat F. Tumor Filóides (Cistossarcoma Filóides). Rev Bras Mastologia. 1999 Mar;9(1):28-33.

5. Calhoum KE, Lawton TJ, Kim JN, Lehman CD, Anderson BO. Phyllodes tumors. In: Harris JR, Lippman ME, Morrow M, Osborne CK. Diseases of the Breast. $4^{\text {a }}$ ed. Philadelphia: Lippincott Williams \& Wilkins; 2010. p.781-92.

6. Lenhard MS, Kahlert S, Himsl I, Ditsch Nina, Untch M, Bauerfeind I. Phyllodes tumour of the breast: Clinical follow-up of 33 cases of this rare disease. Eur J Obstet Gynecol Reprod Biol. 2008;138:217-21.

7. World Health Organization. The World Health Organization: Histological typing of breast tumors - second edition. Am J Clin Pathol. 1982;78:806-916.

8. Azzopardi JG. Sarcoma in the breast. In: Azzopardi JG, editor. Problems in breast pathology. Philadelphia: WB Saunders; 1979. p.346-65.

9. Treves N, Sunderland DA. Cystosarcoma phyllodes of the breast: amalignant and a benign tumor; a clinicopathological study of seventy-seven cases. Cancer. 1951;4(6):1286-332.

10. Norris HJ, Taylor HB. Relationship of histologic features to behavior of cystosarcoma phyllodes analysis of ninety-four cases. Cancer. 1967;20(12):2090-9.

11. Tan HP, Ellis IO. Myoephitelial and epitelial-myoepithelial, mesenchymal and fibroepithelial breast lesions: updates from the WHO Classifications of Tumours of the Breast 2012. J Clin Pathol. 2013;66:465-70.

12. Velásquez-Dohom M, Gamboa-Domínguez A, Medina-Franco H. Phyllodes tumor of the breast: clinicopathologic analysis of 22 cases. Rev Invest Clin. 2013 May-Jun;65(3):214-20.

13. Sawalhi S, Al-Shatti M. Phyllodes tumor of the breast: a restrospective study of the impact of histopathological factors in local recurrence and distant metastasis. Ann Saudi Med. 2013 Mar-Apr;33(2):162-8.

14. Majeski J, Stroud J. Malignant phyllodes tumors of the breast: a study in clinical practice. Int Surg. 2012 Apr-Jun;97(2):95-8.

15. Ward RM, Evans HL. Cystosarcoma phyllodes: a clinicopathologicstudy of 26 cases. Cancer. 1986;58(10):2282-9.

16. Cohn-Cedermark G, Rutqvist LE, Rosendahl I, Silfverswärd C. Prognostic factors in cystosarcoma phyllodes. A clinicopathologic study of 77 patients. Cancer. 1991;68(9):2017-22.

17. Mokbel K, Price RK, Mostafa A, Wells CA, Carpenter R. Phyllodes tumour of the breast: a retrospective analysis of 30 cases. Breast. 1999;8:278-81.

18. Roos WK, Kaye P, Dent DM. Factors leading to local recurrence or death after surgical resection of phyllodes tumours of the breast. Br J Surg. 1999;86:396-9.

19. Hassouna JB, Damak T, Gamoudi A, Chargui R, Khomsi F, Mahjoub S, et al. Phyllodes tumour of the breast: a case series of 106 patients. Am J Surg. 2006;192:141-7.

20. Karim RZ, Gerega SK, Yang YH, Spillane A, Carmalt H, Scolyer RA, et al. Phyllodes tumours of the breast: a clinicopathological analysis of 65 cases from a single institution. Breast. 2009;18:165-70.

21. Belkacemi Y, Bousquet G, Marsiglia H, Ray-Coquard I, Magné N, Malard Y, et al. Phyllodes tumour of the breast. Int J Radiat Oncol Bio. 2008;70(2):492-500.

22. Khosravi-Shari P. Management of non metastatic phyllodes tumour of the breast: Review of the literature. Surg Oncol. 2011;20:e143-8. 